\title{
Inter-annual variability of the effects of intrinsic and extrinsic drivers affecting West Nile virus vector Culex pipiens population dynamics in northeastern Italy
}

\section{Diletta Fornasiero ( $\nabla$ dfornasiero@izsvenezie.it)}

Istituto Zooprofilattico Sperimentale delle Venezie

Matteo Mazzuccato

Istituto Zooprofilattico Sperimentale delle Venezie

Marco Barbujani

Istituto Zooprofilattico Sperimentale delle Venezie

Fabrizio Montarsi

Istituto Zooprofilattico Sperimentale delle Venezie

Gioia Capelli

Istituto Zooprofilattico Sperimentale delle Venezie

Paolo Mulatti

Istituto Zooprofilattico Sperimentale delle Venezie

\section{Research}

Keywords: Mosquitoes, Culex pipiens, population dynamics, West Nile, Italy

Posted Date: January 6th, 2020

DOI: https://doi.org/10.21203/rs.2.20103/v1

License: (c) (i) This work is licensed under a Creative Commons Attribution 4.0 International License.

Read Full License

Version of Record: A version of this preprint was published at Parasites \& Vectors on May 29th, 2020. See the published version at https://doi.org/10.1186/s13071-020-04143-w. 


\section{Abstract}

Background: Vector-borne infectious diseases (VBDs) represent a major public health concern worldwide. Among VBDs, West Nile Virus (WNV) showed an increasingly wider spread in temperate regions of Europe, including Italy. During the last decade, WNV outbreaks have been recurrently reported in mosquitoes, horses, wild birds, and humans, showing great variability in the temporal and spatial distribution pattern. Due to the complexity of the environment-host-vector-pathogen interaction and the incomplete understanding of the epidemiological pattern of the disease, WNV occurrences can be hardly predictable. The analyses of ecological drivers responsible for the earlier WNV reactivation and transmission are pivotal; in particular, variations in the vector population dynamics may represent a key point of the recent success of WNV and, more in general, of the VBDs.

Methods: We investigated the variations of Culex pipiens population abundance using environmental, climatic and trapping data obtained over nine years (2010 to 2018) through the WNV entomological surveillance program implemented in northeastern Italy. An Information Theoretic approach (IT-AIC c ) and model-averaging algorithms were implemented to examine the relationship between the seasonal mosquito growth rates and both intrinsic (e.g. intraspecific competition) and extrinsic (e.g. environmental and climatic variables) predictors, to identify the most significant combinations of variables outlining the Cx. pipiens population dynamics.

Results: Population density (proxy for intraspecific competition) and length of daylight were the predominant factors regulating the mosquito population dynamics; however, also other drivers encompassing environmental and climatic variables had a significant impact, although sometimes counterintuitive and not univocal. The analyses of the single-year datasets, and the comparison with the results obtained from the overall model (all data available from 2010 to 2018), highlighted remarkable differences in coefficients magnitude, sign, and significance. These outcomes indicate that different combinations of factors might have distinctive, and sometimes divergent, effects on mosquito population dynamics.

Conclusions: A more realistic acquaintance of the intrinsic and extrinsic mechanism of mosquito population fluctuations in relation to continuous changes in environmental and climatic conditions is paramount to properly reinforce VBDs risk-based surveillance activities, to plan targeted density control measures and to implement effective early detection programs.

\section{Background}

Climate changes have raised global awareness towards the spread of vector borne infectious diseases (VBDs) at international level [1]. VBDs, and arboviruses in particular, represent an important threat for human and animal health, as also stressed by the widespread diffusion of these pathogens in temperate European countries in the last decade [2-5]. Despite recent intensive research, the behavior and the successful expansion of VBDs have not been fully clarified yet. Due to the complexity of the biological 
cycle of arboviruses, and the limited knowledge of their epidemiological patterns, outbreaks might be temporally and spatially unpredictable [6, 7].

One of the most widely distributed arboviruses in the world is West Nile virus (WNV) [8]. The transmission cycle of WNV includes wild and domestic birds as maintenance hosts, and mosquitoes, primarily belonging to the Culex genus, as vectors. Humans and horses, and other mammals to a lesser extent, are susceptible to WNV, although they are considered dead-end hosts [9]. Usually, infections in humans and horses are asymptomatic; however, some infected subjects may develop disease with symptoms ranging from a mild flu syndrome to severe encephalitis or, in the worst cases, death [9].

WNV has been circulating in the Mediterranean Basin at least since the 1960s [10], and numerous outbreaks in human and equine populations have been witnessed since then. In Italy, the first outbreak of WNV was in 1998, in Tuscany, with 14 neuroinvasive cases in horses and no involvement of the human population [11]. The virus re-appeared in 2008, with 251 outbreaks confirmed in equines located in three different regions in northeast Italy [12]. Since then, WNV has been recurrently detected in horses, wild birds and humans. In northeast Italy, WNV was also detected in pools of Culex pipiens mosquito in 2010, and positive pools were thereafter found every year. Nowadays, WNV is considered endemic in the northeastern Italy [13], and the Cx. pipiens it is deemed as its primary vector [14].

The first national veterinary surveillance system for WNV was implemented in 2001, and was further improved in 2010, after the re-emergence of the virus in northeast Italy. In 2013 a risk-based surveillance approach was attempted by the regional Veterinary Authorities in Veneto and Friuli Venezia Giulia (FVG), and based on the identification of recurrent WNV hotspots in humans, equines and mosquitoes [15]. The plan was annually updated with the areas considered most at risk of WNV reactivation, according to the continuous evolution of the epidemiological situation.

In the last decade, the timing and location of positive cases detected in Veneto and FVG varied consistently. In fact, the distribution of the outbreaks over the years did not seem to follow a predictable pattern, except for a progressively earlier detection of the first positive cases in mosquitoes and horses, and a massive increase in human cases, which peaked in 2018 with 257 confirmed cases [16]. The hypothesis underlying this trend over the years could be related to changes in the several drivers of the disease, including the ecological and biological aspects of the vectors, the virus ecology, the reservoir hosts, and the human population [17-19]. There is a strong need for in-depth studies on the ecology of the environment-host-vector-pathogen interaction, in order to seek which factors could trigger the earlier WNV reactivation. In particular, variations in the vector population dynamics may represent a key point of the recent success of WNV and, more in general, of the VBDs [20].

It is widely acknowledged that the vector population abundance is strongly affected by environmental and climatic variability [18], as well as by intrinsic, density-dependent variables [21, 22], even though no clear patterns of these interactions have emerged from several studies [23]. A thorough knowledge of the ecology of the vector population is the first step to analyse the complex phenomenon of the VBDs in their entirety. 
Hereby, we investigated the variations of $\mathrm{Cx}$. pipiens population abundance using environmental, climatic and trapping data obtained over nine years from WNV entomological surveillance program implemented in northeastern Italy. The seasonal mosquito growth rates were analyzed to evaluate the presence of possible differences among single-year and overall period (i.e. all data available from 2010 to 2018) data analyses, in order to identify the most significant combinations of variables outlining the $C x$. pipiens population dynamics. The great variability in the pattern of occurrence of WNV cases in this territory led us to envisage a potential different response for vector population dynamics to different combinations of environmental conditions; this could affect the distribution pattern of the disease distinctively over the years. Ultimately, a more realistic acquaintance of vector population drivers could offer a baseline information for planning targeted density control measures, improved risk-based surveillance activities and early detection programs.

\section{Methods}

\section{Area and period of study}

The study was conducted exploiting the results of entomological surveillance plans carried out in the flatlands of Veneto (below $300 \mathrm{~m}$ above the sea level) and FVG Regions, northeastern Italy.

Environmental, climatic, and entomological data were collected for the period 2010-2018 for Veneto, and for 2011-2018 for FVG, as entomological surveillance started later in this Region (Fig. 1).

\section{Mosquito data collection}

A variable number of trap sites were operating in the study area each year, accordingly to variations in the Regional Surveillance Plans.

Mosquito captures were conducted using CDC traps baited with dry ice pellets as source of carbon dioxide (IMT® - Italian Mosquito Trap, Cantù, Italy), aiming at attracting blood-meal seeking females and powered by a 12-V battery. Traps were activated overnight every two weeks, from $5 \mathrm{pm}$ to $11 \mathrm{am}$ on following day. The entomological surveillance season ran each year approximately between the first week of May until two consecutive captures with no mosquitoes collected (generally between the last week of October and the first of November).

CDC traps were located mainly in rural/agricultural areas but some natural and urban sites were also included. Collected adult mosquitoes were carried refrigerated to the laboratory and there killed by freezing at $-20^{\circ} \mathrm{C}$ and then identified using a stereomicroscope and taxonomic keys [24].

Only adult females belonging to the Culex pipiens complex (i.e. encompassing both the Cx. pipiens pipiens and $\mathrm{Cx}$. pipiens molestus forms, which are phenotypically indistinguishable) have been included in the analyses, as they are considered the most important WNV vector in Italy [25]. To obtain a more reliable picture of the population dynamics, only traps that had at least four consecutive favourable catches were included in the study. 


\section{Environmental data}

Environmental data were extracted through a system developed at the Istituto Zooprofilattico Sperimentale delle Venezie and named Environmental data for Veterinary Epidemiology (EVE), and included: temperature and vegetation measurements derived from NASA MODIS satellite imagery [26, 27], precipitation derived from interpolation of ground sensors, and length of daylight (Table 1).

Table 1

Extrinsic and intrinsic variables considered in the analysis, and variables included in the $I T-\mathrm{AlC}_{\mathrm{C}}$ models

\begin{tabular}{|c|c|c|}
\hline Variable & Description & $\begin{array}{l}\text { Included in IT-AIC } \\
\text { approach }^{(1)}\end{array}$ \\
\hline GMP & $\begin{array}{l}\text { Density dependent variables measuring the saturation of the } \\
\text { carrying capacity }\end{array}$ & $x$ \\
\hline DT.h & Length of daylight (hours) & $x$ \\
\hline $\mathrm{DMI}_{15 \mathrm{~d}}$ & $\begin{array}{l}\text { De Martonne aridity Index in } 15 \text { days prior to capture (mm/ } \\
\left.{ }^{\circ} \mathrm{C}\right)\end{array}$ & $x$ \\
\hline $\mathrm{GDD}_{15 \mathrm{~d}}$ & Growing degree days in 15 days prior to capture & $\mathrm{x}$ \\
\hline $\mathrm{NDVI}_{15 \mathrm{~d}}$ & $\begin{array}{l}\text { Maximum Normalized Difference Vegetation Index in } 15 \\
\text { days prior to capture }\end{array}$ & $x$ \\
\hline PREC & Daily cumulative precipitation (mm) & $x$ \\
\hline PREC.avg $_{15 d}$ & $\begin{array}{l}\text { Average cumulative precipitation in } 15 \text { days prior to capture } \\
(\mathrm{mm})\end{array}$ & \\
\hline PREC.k $k_{15 d}$ & Precipitation kurtosis in 15 days prior to capture $(\mathrm{mm})$ & $\mathrm{x}$ \\
\hline PREC.sd $15 d$ & $\begin{array}{l}\text { Precipitation standard deviations in } 15 \text { days prior to capture } \\
(\mathrm{mm})\end{array}$ & \\
\hline $\operatorname{T.avg}_{15 d}$ & Average temperature in 15 days prior to capture $\left({ }^{\circ} \mathrm{C}\right)$ & \\
\hline T. $\mathrm{k}_{15 \mathrm{~d}}$ & Temperature kurtosis in 15 days prior to capture $\left({ }^{\circ} \mathrm{C}\right)$ & $\mathrm{x}$ \\
\hline T.sd $_{15 d}$ & $\begin{array}{l}\text { Temperature standard deviations in } 15 \text { days prior to capture } \\
\left({ }^{\circ} \mathrm{C}\right)\end{array}$ & $x$ \\
\hline T.night & $\begin{array}{l}\text { Average temperature recorded during the overnight capture } \\
\text { period }(6 \mathrm{pm}-6 \mathrm{am})\left({ }^{\circ} \mathrm{C}\right)\end{array}$ & $x$ \\
\hline
\end{tabular}

As Cx. pipiens larvae were assumed to develop into adult forms in approximately two weeks [28, 29], we extracted measures concurrent with the capture moments, and summarising values for the 15 days prior to trapping. This allowed describing the potential influence of environmental and climatic factors on both 
adult mosquito dynamics and the development of the larval forms. Synoptic variables included: the average of the distributions of the cumulative daily precipitation (PREC.avg ${ }_{15 d}$ ) and of the daily average temperature $\left(\operatorname{T} \cdot \mathrm{avg}_{15 \mathrm{~d}}\right)$, the De Martonne Index $\left(\mathrm{DMI}_{15 \mathrm{~d}}\right)$, the Normalised Difference Vegetation Index $\left(\mathrm{NDVI}_{15 \mathrm{~d}}\right)$, and the Growing Degree Days $\left(\mathrm{GDD}_{15 \mathrm{~d}}\right)$. Furthermore, since mosquitoes had been observed being sensitive to fluctuations in weather trends [30], also measures of climatic variability were included in the analyses to better investigate associations between mosquito dynamics and their drivers. Beside average measurements, also the kurtoses and standard deviations of the distributions of cumulative daily precipitations (PREC. $k_{15 d}$ and PREC.sd ${ }_{15 d}$ ), and of the daily average temperature (T. $k_{15 d}$ and \left.${\mathrm{T} . s d_{15 d}}_{1}\right)$ in the 15 days prior captures were taken into account, to evaluate whether the extent of climatic variation may influence the mosquito growth rates, during the assumed larval development period.

The De Martonne index provides information on the overall level of aridity of an area [31]. Values lower than 20 are considered indicative of arid or semi-arid lands. The formula proposed for monthly estimates [32] was adapted to account for only 15 days prior to capture as follow:

$$
D M I_{15 d}=\frac{24.3 * P R E C_{15 d}}{T^{a v g} g_{15 d}+10}
$$

Where PREC ${ }_{15 d}$ and $\mathrm{T} . a v g_{15 d}$ are the cumulative precipitation and the average temperature in 15 days, respectively, and 24.3 is a scaling factor to account for calculation of DMI at a 15 days scale.

As NDVI showed negligible variation in time, in each single capture season, only the maximum values observed within $1 \mathrm{~km}$ from the capture sites in the 15 days prior to the trappings were included in further analyses.

The Growing Degree Days (GDD) were considered to capture the direct effect of temperature on development cycle of mosquitoes. GDD estimates were considering a defined range for mosquito activity $[23,33]$. A lower threshold (LT) was set at $11.5^{\circ} \mathrm{C}$ and an upper threshold (UT) at $34.7^{\circ} \mathrm{C}$, accounting for corrections for average differences between air temperatures and the land surface temperatures (LST). GDD daily values were calculated as:

$$
\begin{cases}0 & \text { if } T<L T \\ T-L T & \text { if } T \geq L T \text { and } T \leq U T \\ U T & \text { if } T>U T\end{cases}
$$

where T is mean daily LST.

Four daily values of LST were available for each trapping day, recorded at 1:30 pm and 10:30 pm on the day in which the trap was positioned, and at 1:30 am and 10:30 am on the following day. The four measurements were combined to obtain an estimate of the average temperature during the period of 
most intense Cx. pipiens activity, which was observed occurring between $6 \mathrm{pm}$ and 6 am in this area (T.night) $[34,35]$.

To capture the effect of diapause and the suppression of feeding behaviour on mosquito population [36, 37], the length of daylight was included in the analyses (DT.h). In fact, the start and end of diapause had been described as strongly related to photoperiod, indicating that $\mathrm{Cx}$. pipiens mosquitoes could enter a quiescent period when the length of daylight decreases [36]. The length of daylight was retrieved from the repositories of the Astronomical Applications Department of the U.S. Naval Observatory.

\section{Statistical analyses}

To investigate the trends of the mosquito population abundance over the years, growth rates were calculated at each capture site. Mosquito abundances were processed to compute the geometric moving average on three consecutive captures, allowing to flatten short term fluctuations and highlight longer term trends. The per-capita growth rate was then computed as:

$$
r_{t}=\log \frac{N_{t+1}}{N_{t}}
$$

Where $N_{t}$ is the averaged population density at time $t, N_{t+1}$ is the averaged population density at the succeeding capture.

A series of statistical models was fitted using Maximum Likelihood mixed-effects linear regression (Linear Mixed-Effects model, LME) [38], to evaluate the influence of the environmental and climatic drivers on the mosquito growth rate trends. An additional density-dependent variable was included in the analysis, considering that the growth rates could follow a Gompertz-logistic model, which accounts for the saturation of the carrying capacity at each capture site $[23,39]$. Accordingly to the Gompertz model, the density dependent variable (indicated as GMP) was calculated as:

$$
G M P=\frac{\log (N)}{\log (K)} \quad ;
$$

where $\mathrm{N}$ is the abundance of mosquitoes per capture and $\mathrm{K}$ is the carrying capacity, which was assumed to vary through years and capture sites, and was set as the most abundant capture recorded for each year and site.

Data were grouped per capture sites and year, as nested random effects, as we assumed that growth rates might vary among different capture sites, and for each site, the growth rates might vary in different years. Before model fitting, all variables included in the statistical analyses were scaled and centered to allow easier inferences through the direct comparison of the coefficients estimates: higher absolute values of the estimates indicate stronger effects on the population growth rates [40]. A temporal autocorrelation structure was also considered, to handle repeated measurements and seasonal data, 
allowing to account for the presence of potential serial correlation of the residuals. A series of statistical models were then built to investigate the effects of intrinsic and extrinsic drivers on the mosquito population dynamics. In particular, one model was fit including all data collected during the whole study period (2010-2018), while nine other models were fit on single-year data, separately. These full initial models were built including the GMP variable, and the environmental and climatic variables (Table 1). Further sets of models were then generated considering all of the possible combinations of variables.

Model selection was based on the Information Theoretic (IT) approach [41] based on the corrected Akaike Information Criterion (IT-AIC ${ }_{C}$ ) [41-43]. The IT-AIC ${ }_{c}$ approach is based on a comparative fit analysis through the calculation of Akaike weights ( AAIC $_{c}$ ) for each generated model, and can be interpreted as

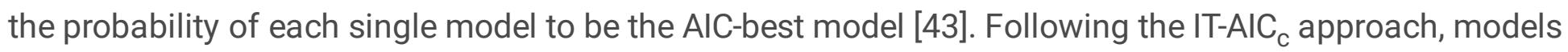
within each set were compared to assess whether there was a single model with high statistical support or many models with similar fit. In the absence of a single outperforming model, model averaging was performed, combining the parameter estimates from the selected set of models considering the contribution of each model being proportional to its likelihood weight [41, 43]. For each generated set of models, a subset was selected so that their total cumulative $\mathrm{WAIC}_{\mathrm{c}}$ was equal to 0.95 . This subset of models was assumed to include the $\mathrm{AIC}_{\mathrm{C}}$-best model, with a probability of 0.95 . Furthermore, the number of selected models provides information on the level of uncertainty encountered. From models with averaged coefficients, the relative importance of each single predictor variable was calculated as the sum of the $\mathrm{AIC}_{\mathrm{c}}$ weights over all of the models in which the variable of interest appeared [43].

The linear mixed-effect models were fitted using the nlme package [44], the IT-AIC ${ }_{c}$ approach was performed through the package MuMIn [45], in the R statistical software version 3.5.2 [46].

\section{Results}

\section{Annual trends in mosquito catches and abundance, and in environmental and climatic factors}

The average abundance of captured mosquitoes varied significantly between several years $\left(\mathrm{F}_{8,4899}=\right.$ 28.55, $p<0.001$; Figure S1.A). Overall mosquito captures were most abundant in 2013 ( $p<0.05$ for all of the comparisons), followed by trappings done in 2010. Conversely, 2011 in particular, but also 2015, 2017, and 2018 were the least abundant years. Despite several statistical differences observed in the population consistency, the mosquito growth rates did not vary significantly among years $\left(F_{8,4899}=0.70\right.$, $p=0.697)$. Statistical differences were observed for the density-dependent variable $\left(F_{8,4899}=4.83, p<\right.$ 0.001), post-hoc tests showed an overall higher value for 2018 (compared with 2010, 2013 and 20152017), and lower estimates for 2017 when compared with 2011, 2014, and 2018 (Figure S1.B). 
The precipitations concurrent with the trapping nights resulted significantly varying throughout the whole period of study $\left(\mathrm{F}_{8,4899}=12.70, \mathrm{p}<0.001\right)$, with post-hoc Tukey's test indicating similar higher values for 2014 and 2015 (Figure S1.C). Significant between-year differences were also detected for cumulative precipitations on 15 days prior to trappings $\left(F_{8,4899}=17.90, p<0.001\right)$, and the higher values were recorded in 2010 and 2014 (Figure S1.D). Both temperatures concurrent with the trapping nights and average temperatures recorded 15 days before captures showed significant differences $\left(F_{8,4899}=27.73\right.$, $p<0.001$ and $F_{8,4899}=43.16, p<0.001$, respectively). Overall, night temperatures concurrent with mosquito captures, and average temperatures in 15 days before trapping were markedly lower for 2010 with respect to other years, and for 2014 in comparison with 2015-2018. In contrast, 2018 showed the warmest temperatures in the whole period of study (on average, $+2.79^{\circ} \mathrm{C}$ on the concurrent night and + $2.88^{\circ} \mathrm{C}$ in the 15 days before capture, compared to the other years. Figure S1.E and Figure S1.F). Also the level of aridity significantly varied by years $\left(\mathrm{F}_{8,4899}=17.97, \mathrm{p}<0.001\right)$. Post-hoc tests indicated a similar trend with the average precipitation in 15 days: 2010 and 2014 showed an overall higher $\mathrm{DMI}_{15 \mathrm{~d}}$, indicating lower aridity levels (Figure S1.G). As for $\mathrm{NDVI}_{15 \mathrm{~d}}\left(\mathrm{~F}_{8,4899}=18.90, \mathrm{p}<0.001\right)$, significantly lower values were observed in 2012 and 2013, while a generally more abundant vegetation was repeatedly reported for 2014, 2015, and 2018 (Figure S1.H).

\section{Drivers of mosquito population growth rates}

Preliminary analyses indicated the presence of a high correlation between some environmental variables (Table S1). Therefore, before model fitting, the average values of precipitations and temperatures were excluded, due to a high correlation with PREC.sd ${ }_{15 d}$ and $\mathrm{DMI}_{15 \mathrm{~d}}$, and with $\mathrm{GDD}_{15 \mathrm{~d}}$, respectively. Variance Inflation Factors (VIFs) were calculated on a preliminary model fitted with the remaining variables, resulting in high VIF for $\mathrm{DMI}_{15 \mathrm{~d}}$ and PREC.sd ${ }_{15 \mathrm{~d}}$ (9.24 and 7.72, respectively), indicating potential collinearity. Following further exploratory GLMM considering either $\mathrm{DMI}_{15 \mathrm{~d}}$ or PREC.sd $\mathrm{d}_{15 \mathrm{~d}}$ alone as independent variables, the model accounting for $\mathrm{DMI}_{15 \mathrm{~d}}$ as predictor of the growth rates showed greater statistical support $\left(\right.$ WAIC $\left._{c}=0.68\right)$. Therefore, we excluded PREC.sd ${ }_{15 d}$ from further analyses.

All of the initial models were then built including ten explanatory variables: GMP, DT.h, PREC, PREC.k ${ }_{15 d}$,

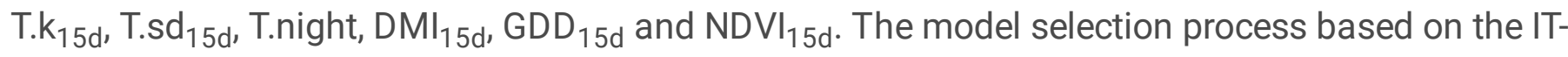
approach generated 1024 models for each year and for the whole period (2010-2018), encompassing all of the possible combinations of explanatory variables. For each set, different numbers of models were necessary to reach a total cumulative WAIC $_{C}$ of at least 0.95 (Table 2). The subsets ranged from a minimum of 70 models for 2015 to a maximum of 195 models for 2017, indicating different levels of uncertainty among years. 
Table 2

Number of selected models for each subset, with cumulative AAIC $_{c}=0.95$

\begin{tabular}{|llllllllll|}
\hline $\mathbf{2 0 1 0 - 2 0 1 8}$ & $\mathbf{2 0 1 0}$ & $\mathbf{2 0 1 1}$ & $\mathbf{2 0 1 2}$ & $\mathbf{2 0 1 3}$ & $\mathbf{2 0 1 4}$ & $\mathbf{2 0 1 5}$ & $\mathbf{2 0 1 6}$ & $\mathbf{2 0 1 7}$ & $\mathbf{2 0 1 8}$ \\
\hline 84 & 106 & 152 & 129 & 79 & 104 & 70 & 92 & 195 & 107 \\
\hline
\end{tabular}

Significant results are shown in Fig. 2; supplementary Table S2 reports the coefficients estimates and importance for all the variables included in the averaged models.

The highest absolute values for the coefficients were associated with length of daylight (DT.h) and with the density-dependent (GMP). Coefficients of daylight were always positive and ranged between 0.657 and 1.251 , suggesting that higher growth rates were observed when days were longer. The density of mosquitoes had always a negative sign, implying an inverse influence on the growth rates, allowing to inference that growth rates decreased when the carrying capacity was saturating. Both DT.h and GMP were always highly significant $(p<0.001)$, and had maximum importance (i.e. importance $=1$ ), which indicated they were included in all of the models selected for the averaging process.

Precipitation values concurrent with mosquito trapping were not significant in any set of models. As factors measured on the day of capturing did not provide indications on the effects on growth rates, but more on how the adult mosquitoes were affected, the results suggested rainfall likely did not influence the captures of adult mosquitoes. As for the variables summarizing the variation of rainfall during larval development, the kurtosis of the distribution of cumulative precipitation values was significant only for $2015(p<0.001)$, although the coefficient was not as large as those observed for DT.h and GMP (Coef. = 0.048). The positive coefficient suggested that increases in growth rates were more likely when the cumulative rainfall followed a leptokurtic distribution, which indicated that periods characterized by a more homogeneous rainfall may favor larval development and consequently the population growth rate.

The coefficient for the $\mathrm{GDD}_{15 \mathrm{~d}}$ was significant and highly important in 2014 and $2018(\mathrm{p}<0.05$, importance $=0.92$ and 0.95 respectively), with negative coefficients $(2014$, Coef. $=-0.175 ; 2018$, Coef. $=$ $-0.102)$. Conversely, the coefficient for $2011(p<0.1)$ was positive, although with a relatively smaller effect on the growth rate (Coef. $=0.081)$.

Sensible variations in temperatures during larval development appeared to be positively correlated to mosquito population dynamics in 2014 (Coef. $=0.042, p<0.1$ ), while an opposite effect was observed for 2016 (Coef. $=-0.047, p<0.001$ ). Overall temperatures in 2014 were, on average, significantly lower, and characterized by the smallest average of standard deviations, which corresponds to a smaller range of temperatures. This means that 2014 was characterized by a cooler summer and a less harsh winter. The results of our analyses suggested that even small rises in temperatures during an averagely cooler period may lead to increased growth rates, as it probably promotes the development of larval forms. On the contrary, in 2016 temperatures did not present peculiar trends compared to the other years, although temperatures seem to decrease less steeply after the July peak. The slower decrease of summer 
temperatures may have determined a prolonged period characterized by more homogeneous temperatures, which may have been more favorable for the mosquito growth.

The average temperature during the captures (wT) had a significant contribution on growth rates for 2010 and 2012 only, with a negative effect (Coef. $=-0.114$ and $-0.082, p<0.01$ and $p<0.05$ for 2010 and 2012, respectively; importance $>0.90$ for both years). No other variables related to temperature appeared to have a significant influence on mosquito population dynamics.

The coefficients for the De Martonne Index was significant for the averaged model built for 2013 (Coef. = $-0.052, p<0.01$, importance $=0.99$ ), and for 2018 (Coef. $=0.049, p<0.1$, importance $=0.91$ ). A smaller effect was also observed for the whole period of study (Coef. $=0.014, p<0.1$, importance $=0.92$ ).

A positive coefficient of 0.040 for the $\mathrm{NDVI}_{15 \mathrm{~d}}$ was highly significant $(\mathrm{p}<0.001)$ and important (importance $=1.00$ ) in the averaged model built for the entire study period $(2010-2018)$. As for singleyear averaged models, the coefficient estimates showed high importance (Imp. >0.80) only for years 2013-2016, and ranged between 0.064 (2016) and 0.100 (2013).

Supplementary Figure S2 shows annual trends for temperature, aridity and vegetation indexes to improve the interpretation of the results of our study.

\section{Discussion}

In-depth knowledge of mosquito population dynamics and variability over time is paramount to understand how WNV infections might spread on an area. Although Cx. pipiens population dynamics are known to be regulated by both density-dependent and climatic and environmental factors [23, 47, 48], the complexity of its ecology hampers the capacity to assess univocally to what extent the key drivers regulate the population dynamics. The great variability observed in both the number and distribution of WNV cases in Italy over the years, laid the basis for speculating that year to year variations in environmental and climatic factors, and their combinations, could induce diverse responses in mosquito dynamics, ultimately affecting the pattern of occurrence of WNV cases.

In this study, we aimed at evaluating whether the effect of environmental, climatic, and density dependent factors affected the population dynamics in a consistent way, year by year, or if there were variations on how vector populations responded along the nine years of our study period.

From our results, it emerged that only two factors were regularly detected in the models, indicating consistency in how they are associated with $\mathrm{Cx}$. pipiens population dynamics: the first, population density, appeared having always a negative effect, while the second, length of daylight, had a positive influence on growth rate. The negative sign associated with the density-dependent variable reflects the trend of the growth rates saturation curve as described by a Gompertz-logistic model [39]: the growth rates decrease as the mosquito density reaches the population carrying capacity. The impact of population density stresses the relevance of endogenous factors in regulating the internal dynamics of 
Cx. pipiens population $[48,49]$, however, they may be not completely sufficient to explain entirely the variation observed.

The length of daylight had the strongest effect, with positive coefficients, indicating that growth rates were higher when in periods with a higher number of light hours, and dropped when photoperiod decreased. This could be related with changes in the mosquito behavior $[49,50]$, as females prepare for the diapause and stop searching for blood meals, opting for a more sugary diet [51].

The effect of precipitation was appreciable only for one model out of ten, stressing the uncertainty already reported in literature on the effect of rainfall on mosquito populations $[49,52]$. In general, is acknowledged that precipitations could contribute to create small basins of enriched water, suitable as reproductive foci for mosquitoes [30]. Also, since larval stages are water-dependent, precipitation could play an important role in creating and maintaining the wet environment necessary for the development of mosquitoes [53]. On the contrary, an excess of rainfall flushes the development foci used by larvae, leading to a decrease in the number of adult mosquitoes at a later moment, determining a reduction in the population growth rates $[30,54]$.

Of the two factors we included in the model to account for the variability of temperatures during the larval development period, only the standard deviation appeared to be significantly associated with variations in mosquito growth rates, although its effect was not univocal. This was also observed in other studies, which inferred that environmental drivers such as temperature might have complex and opposing impacts on the demographic rates of mosquitoes life cycle stages [55]. Overall, increasing temperatures lead to a faster development of the immature stages and stimulate the flight activity of Cx. pipiens, but too much heath could dry up the eggs and larvae, as well as decreasing the lifespan of adults. As for the Growing Degree Days, within certain limits, higher $\mathrm{GDD}_{15 \mathrm{~d}}$ appeared to significantly determine a greater growth rate, as the accumulated heath allowed eggs and larvae to develop into adult stage, so a larger number of adult mosquitoes can be trapped in the succeeding capture. However, when the amount of $\mathrm{GDD}_{15 \mathrm{~d}}$ is very high, it could also lead to an apparent decrease in growth rates. In fact, the generally positive effect of temperature could shorten the time needed for larvae to develop into adult form [37], therefore it would be possible that in 15 days more than a generation of adults could develop, determining an overlapping of multiple generations of mosquitoes. The increase in population abundance would then cause a reduction of growth rates due to the density-dependent effect, as the carrying capacity is rapidly saturated.

The effect of average overnight temperature appeared to be in contrast with what already reported in literature, which reported that temperatures are positively linked to mosquitoes abundance $[49,52,56]$. Our observation suggested that night temperatures alone might be not sufficient to account for the variations observed in the trapped adult mosquitoes, and likely unaccounted interactions with other environmental/ecological factors could be imputable for the negative effect found. A definitive explanation for this relationship remains elusive, and further studies might be needed to investigate this apparent discrepancy in the nature of temperature effects. 
Contrasting effects were also detected for the De Martonne Index, which described the effect of arid environment. Overall, it appeared that a more humid environment is positively associated with increased growth rates, although the finding was significant only for the overall period model and for 2018 . The negative impact of $\mathrm{DMI}_{15 \mathrm{~d}}$ on mosquito population dynamics for 2013 , although counterintuitive, could be partially explained when looking at the precipitation and temperature trend of that year. In fact, 2013 was characterised by a warmer and rainy spring followed by an exceptionally dry and arid summer. Heavy rainfall in spring might have contributed in creating suitable ecological niches for the development of larval stages, which in turn could have led to an increase in the abundances of adult mosquitoes at the beginning of the entomological surveillance season. This might have elicited a faster saturation of the population carrying capacity, with a consequential decrease of the growth rates due to the density dependent effect. Another potential explanation could be related to the fact that drought conditions during the catching season might have contributed to enrich with organic material the existing development foci, through evaporation, creating a more suitable environment for mosquito larvae to thrive $[54,57]$. In addition, in periods of drought, artificial irrigation is more frequent especially for wheat and corn fields, which are particularly abundant in north-eastern Italy. The continuous availability of water provides suitable Cx. pipiens larval foci, and in turn higher growth rates and WNV diffusion [58].

The results for the measurements of biomass $\left(\mathrm{NDVI}_{15 \mathrm{~d}}\right)$ were consistent with other studies, where similar effects were observed [30,52]. High estimates of NDVI in rural/agricultural areas had been put into relationship with the presence of breeding and resting sites suitable for $\mathrm{Cx}$. pipiens mosquitoes, also providing a source of organic matter and nutrients necessary for the developing of the immature stages [59].

Overall, the results of the models highlighted that population density and daylight were the predominant factors regulating the mosquito population dynamics, as they appeared in all of the models with the highest coefficients and direct effects. Other drivers encompassing environmental and climatic variables also had an impact, although sometimes counterintuitive and not univocal. Analysing single-year datasets and comparing the results to overall period models, highlighted remarkable differences in coefficients magnitude, sign, and significance. In fact, it could be argued that mosquito populations may respond in different ways to fluctuations of environmental conditions, according to different variables combinations over the years. The inclusion of factors indicating environmental variability was useful to investigate association patterns between mosquito dynamics and climatic trends, as also seen in other Countries [30], where population densities appeared being positively correlated to increased variability in both temperature and rainfall. However, in our study this resulted only for years in which climatic factors appeared to be extreme, and thus unfavourable for $\mathrm{Cx}$. pipiens growth. Therefore, when environmental conditions are more suitable for mosquito populations, a more homogeneous trend was positively associated with increased growth rates.

The sets of models selected per year, with a cumulative wAIC $_{c}$ of at least 0.95 , were always markedly conspicuous. This output of the IT-AIC ${ }_{c}$ approach reflected the high level of uncertainty in defining single best models for each year of analysis. However, to limit the complexity of the initial models, and hence 
the potential uncertainty in results, interactions between variables were not taken into account in the models, as well as quadratic or non-linear effects for variables as temperature and temperature-derived factors, which could actually have a non-linear influence on mosquito population dynamics. Further study would be required to investigate how to incorporate more complex variables to model the population dynamics.

An acknowledged limitation of our study was related to the source of mosquito data, which derived from the Regional WNV entomological Surveillance Plan. The surveillance activities had a precise start date, which likely did not catch the exact beginning of the mosquito season after the end of the wintry diapause. This could hamper the model statistical support, as it was not possible to assess how the intrinsic and extrinsic drivers influenced the population dynamics in the earliest phases. The availability of mosquito data collection for the entire non-diapause period of $\mathrm{Cx}$. pipiens could improve the robustness of the models, and soundness of inferences made upon them. Another aspect to be recognised is related to the different number of capture sites in the nine years of study and their variable position throughout the study period, in accordance with the needs and requirements of the Regional WNV Surveillance Plan. In fact, inconsistencies in the trapping patterns might introduce artefacts and biases, indicating variations that may not necessarily reflect the actual fluctuations in local population dynamics during the study period [30]. To overcome this issue and limit as much as possible any loss in performance, we considered environmental and climatic factors measured at each capture site during the trappings and the two weeks before. This would help to capture the actual influence of the location on the mosquito population dynamics.

\section{Conclusions}

The current study provides an extensive insight into the $\mathrm{Cx}$. pipiens population dynamics in northeastern Italy, an area considered endemic for WNV. The availability of large dataset with entomological, environmental, and climatic data over a 9-years period, allowed the estimation of the contribution of the most important drivers on the regulation of the population dynamics, highlighting interesting ecological differences among years. One of the most interesting results indicates that an overall model on the whole study period might be excessively generic, not allowing to assess the granularity of the effect of environment and climate on mosquito populations along the whole study period. In fact, differences were detected in environmental/climatic drivers in single-year models, allowing inferring that different combinations of factors or different trends of factors might have distinctive, and sometimes divergent, influences on mosquito dynamics.

Enhancing the understanding of the intrinsic and extrinsic mechanism of mosquito population fluctuations in relation to continuous changes in environmental conditions is paramount to properly reinforce risk-based surveillance programmes and control measures. The capacity to identify areas where an increased mosquito population density should be expected would allow triggering targeted countermeasures such as disinfestations, as well as suggesting where to capture mosquitoes to optimise resources for entomological WNV surveillance. 


\section{Abbreviations}

DMI: De Martonne Index; GDD: Growing Degree Days; IT-AIC : Information Theoretic methodologies based on the corrected Akaike Information Criterion; LME: Linear Mixed-Effects model; LST: land surface temperatures; NDVI: Normalized Difference Vegetation Index; VBDs: Vector Borne diseases; WAIC $_{\mathrm{c}}$ : Akaike weights; WNV: West Nile virus;

\section{Declarations}

\section{Ethics approval and consent to participate}

Not applicable

\section{Consent for publication}

Not applicable

\section{Availability of data and material}

The datasets used and/or analysed during the current study are available from the corresponding author on reasonable request.

\section{Competing interests}

The authors declare that they have no competing interests

\section{Funding}

The study was financially supported by the Italian Ministry of Health (project code: IZS VE 03/15 RC), and by the Regional Prevention Plan entitled "Entomological Surveillance of vector-borne diseases in Veneto Region" (Regional Committee resolution n. 1194 of 2017).

\section{Authors' contributions}

DF conducted the data analyses and wrote the manuscript. MM and MB managed and elaborated the environmental data and contributed with drafting the materials and methods. GC and FM supervised the mosquito trapping activities, provided the captures data and contributed in discussing the results. PM contributed in designing the study, interpreting the results from the models and supervised the drafting of the manuscript. All authors read and approved the final manuscript.

\section{Acknowledgments}

The authors wish to thank Dr. Stefano Marangon for useful insights in interpreting the results. We wish also to thank all the staff involved in the mosquito trapping activities and laboratory identification. 


\section{Authors' information}

${ }^{1}$ Istituto Zooprofilattico Sperimentale delle Venezie, Viale dell'Università 10, 35020 Legnaro (Padua), Italy.

\section{References}

1. Rogers DJ, Randolph SE. Climate change and vector-borne diseases. Adv Parasitol. 2006; 62:34581.

2. Messina JP, Brady OJ, Golding N, Kraemer MUG, Wint GRW, Ray SE, et al. The current and future global distribution and population at risk of dengue. Nat Microbiol. 2019; 4:1508-15.

3. Bartlow AW, Manore C, Xu C, Kaufeld KA, Del Valle S, Ziemann A, et al. Forecasting Zoonotic Infectious Disease Response to Climate Change: Mosquito Vectors and a Changing Environment. Vet Sci. 2019; 6:40.

4. Jánová E. Emerging and threatening vector-borne zoonoses in the world and in Europe: a brief update. Pathog Glob Health. 2019; 113:49-57.

5. Aguirre AA. Changing Patterns of Emerging Zoonotic Diseases in Wildlife, Domestic Animals, and Humans Linked to Biodiversity Loss and Globalization. ILAR J. 2017; 58:315-8.

6. Gao X, Liu H, Li X, Fu S, Cao L, Shao N, et al. Changing Geographic Distribution of Japanese Encephalitis Virus Genotypes, 1935-2017. Vector-Borne Zoonotic Dis. 2019; 19:35-44.

7. Zeller HG, Schuffenecker I. West Nile Virus: An Overview of Its Spread in Europe and the Mediterranean Basin in Contrast to Its Spread in the Americas. Eur J Clin Microbiol Infect Dis. 2004; 23:147-56.

8. Kramer LD, Styer LM, Ebel GD. A global perspective on the epidemiology of West Nile virus. Annu Rev Entomol. 2008; 53:61-81.

9. Mackenzie JS, Gubler DJ, Petersen LR. Emerging flaviviruses: the spread and resurgence of Japanese encephalitis, West Nile and dengue viruses. Nat Med. 2004; 10:S98-109.

10. Calistri P, Giovannini A, Hubalek Z, lonescu A, Monaco F, Savini G, et al. Epidemiology of west nile in Europe and in the mediterranean basin. Open Virol J. 2010; 4:29-37.

11. Autorino GL, Battisti A, Deubel V, Ferrari G, Forletta R, Giovannini A, et al. West Nile virus Epidemic in Horses, Tuscany Region, Italy. Emerg Infect Dis. 2002; 8:1372-8.

12. Monaco F, Lelli R, Teodori L, Pinoni C, Di Gennaro A, Polci A, et al. Re-emergence of West Nile virus in Italy. Zoonoses Public Health. 2010; 57:476-86.

13. Monaco F, Savini G, Calistri P, Polci A, Pinoni C, Bruno R, et al. 2009 West Nile disease epidemic in Italy: first evidence of overwintering in Western Europe? Res Vet Sci. 2011; 91:321-6.

14. Romi R, Pontuale G, Clufolini MG, Fiorentini G, Marchi a, Nicoletti L, et al. Potential vectors of West Nile virus following an equine disease outbreak in Italy. Med Vet Entomol. 2004; 18:14-9.

15. Mulatti P, Mazzucato M, Montarsi F, Ciocchetta S, Capelli G, Bonfanti L, et al. Retrospective spacetime analysis methods to support West Nile virus surveillance activities. Epidemiol Infect. 2014; 1- 
12.

16. Mulatti P, Montarsi F, Cunial G, Da Rold G, Fornasiero D, Gagliazzo L, et al. West Nile Virus in Northeastern Italy: Preliminary Results of Surveillance Activities in 2018. In: Ricciardi W, Marcheggiani S, Puccinelli C, Carere M, Sofia T, Giuliano F, et al., editors. First Sci Symp - Heal Clim Chang. Rome, December 3-5, 2018: ISTISAN CONGRESSI 18/C5; 2018. p. 20-1.

17. Ruiz MO, Walker ED, Foster ES, Haramis LD, Kitron UD. Association of West Nile virus illness and urban landscapes in Chicago and Detroit. Int J Health Geogr. 2007;6:10.

18. Bisanzio D, Giacobini M, Bertolotti L, Mosca A, Balbo L, Kitron U, et al. Spatio-temporal patterns of distribution of West Nile virus vectors in eastern Piedmont Region, Italy. Parasit Vectors. BioMed Central Ltd; 2011;4:230.

19. Owen J, Moore F, Panella N, Edwards E, Bru R, Hughes M, et al. Migrating Birds as Dispersal Vehicles for West Nile Virus. Ecohealth. 2006; 3:79-85.

20. Kilpatrick AM, Kramer LD, Jones MJ, Marra PP, Daszak P. West Nile virus epidemics in North America are driven by shifts in mosquito feeding behavior. PLoS Biol. 2006; 4:e82.

21. Russell TL, Lwetoijera DW, Knols BGJ, Takken W, Killeen GF, Ferguson HM. Linking individual phenotype to densitydependent population growth: The influence of body size on the population dynamics of malaria vectors. Proc R Soc B Biol Sci. 2011; 278:3142-51.

22. Yang G-J, Bradshaw CJA, Whelan PI, Brook BW. Importance of endogenous feedback controlling the long-term abundance of tropical mosquito species. Popul Ecol. 2008; 50:293-305.

23. Mulatti P, Ferguson HM, Bonfanti L, Montarsi F, Capelli G, Marangon S. Determinants of the population growth of the West Nile virus mosquito vector Culex pipiens in a repeatedly affected area in Italy. Parasites and Vectors. 2014; 7:1-11.

24. Severini F, Toma L, Di Luca M, Romi R. Le Zanzare Italiane: Generalità E Identificazione Degli Adulti (Diptera, Culicidae). Fragm Entomol. 2009; 41:213.

25. Romi R, Pontuale G, Clufolini MG, Fiorentini G, Marchi A, Nicoletti L, et al. Potential vectors of West Nile Virus following an equine disease outbreak in Italy. Med Vet Entomol. 2004; 18:14-9.

26. Justice CO, Vermote E, Townshend JRG, Defries R, Roy DP, Hall DK, et al. The Moderate Resolution Imaging Spectroradiometer (MODIS): land remote sensing for global change research. IEEE Trans Geosci Remote Sens [Internet]. 1998; 36:1228-49.

27. Neteler M. Estimating Daily Land Surface Temperatures in Mountainous Environments by Reconstructed MODIS LST Data. Remote Sens [Internet]. 2010; 2:333-51.

28. Horsfall WR. Mosquitoes: their bionomics and relation to disease. New York: Haftner Pub. Co.; 1972.

29. Henn JB, Metzger ME, Kwan J a, Harbison JE, Fritz CL, Riggs-Nagy J, et al. Development time of Culex mosquitoes in stormwater management structures in California. J Am Mosq Control Assoc. $2008 ; 24: 90-7$.

30. Poh KC, Chaves LF, Reyna-Nava M, Roberts CM, Fredregill C, Bueno R, et al. The influence of weather and weather variability on mosquito abundance and infection with West Nile virus in Harris County, 
Texas, USA. Sci Total Environ [Internet]. The Authors; 2019; 675:260-72.

31. de Martonne E. Une nouvelle fonction climatologique: L'indice d'aridité. La Meteorol. 1926; 2:449-58.

32. Baltas E. Spatial distribution of climatic indices in northern Greece. Meteorol Appl [Internet]. 2007; 14:69-78.

33. Clements AN. Biology of mosquitoes. Volume 1: Development, nutrition and reproduction. London: Chapman \$ Hall; 1992.

34. Anderson JF, Main AJ, Ferrandino FJ, Andreadis TG. Nocturnal Activity of Mosquitoes (Diptera: Culicidae) in a West Nile Virus Focus in Connecticut. J Med Entomol. 2007; 44:1102-8.

35. Montarsi F, Mazzon L, Cazzin S, Ciocchetta S, Capelli G. Seasonal and daily activity patterns of mosquito (Diptera: Culicidae) vectors of pathogens in Northeastern Italy. J Med Entomol. 2015; 52:56-62.

36. Vinogradova EB. Diapause in Aquatic Insects, with Emphasis on Mosquitoes. In: Alekseev VR, de Stasio BT, Gilbert JJ, editors. Diapause Aquat Invertebr Theory Hum Use. Dordrecht, The Netherlands: Springer; 2007. p. 83-113.

37. Ewing DA, Purse B V., Cobbold CA, Schäfer SM, White SM. Uncovering mechanisms behind mosquito seasonality by integrating mathematical models and daily empirical population data: Culex pipiens in the UK. Parasit Vectors [Internet]. Parasites \& Vectors; 2019; 12:74.

38. Pinheiro JC, Bates DM. Mixed-Effects Models in S and S-PLUS. New York: Springer; 2000.

39. Tjørve KMC, Tjørve E. The use of Gompertz models in growth analyses, and new Gompertz-model approach: An addition to the Unified-Richards family. Merks RMH, editor. PLoS One [Internet]. 2017; 12:e0178691.

40. Seber GAF, Lee AJ. Linear Regression Analysis. New York: John Wiley and Sons, Ltd; 2003.

41. Burnham KP, Anderson DR. Model Selection and Multi-Model Inference: a Practical InformationTheoretic Approach. 2nd ed. New York: Springer; 2002.

42. Johnson JB, Omland KS. Model selection in ecology and evolution. Trends Ecol Evol. 2004; 19:1018.

43. Whittingham MJ, Stephens PA, Bradbury RB, Freckleton RP. Why do we still use stepwise modelling in ecology and behaviour? J Anim Ecol. 2006; 75:1182-9.

44. Pinheiro J, Bates D, DebRoy S, Sarkar D, R Development Core Team. nlme: Linear and Nonlinear Mixed Effects Models. 2018.

45. Barton K. MuMIn: Multi-Model Inference. 2018.

46. R Development Core Team. R: A language and environment for statistical computing. Vienna, Austria: R Foundation for Statistical Computing; 2019.

47. Yang G-J, Brook BW, Whelan PI, Cleland S, Bradshaw CJA. Endogenous and exogenous factors controlling temporal abundance patterns of tropical mosquitoes. Ecol Appl. 2008; 18:2028-40.

48. Wilke ABB, Medeiros-Sousa AR, Ceretti-Junior W, Marrelli MT. Mosquito populations dynamics associated with climate variations. Acta Trop [Internet]. Elsevier B.V.; 2017; 166:343-50. 
49. Groen TA, L'Ambert G, Bellini R, Chaskopoulou A, Petric D, Zgomba M, et al. Ecology of West Nile virus across four European countries: empirical modelling of the Culex pipiens abundance dynamics as a function of weather. Parasit Vectors [Internet]. Parasites \& Vectors; 2017; 10:524.

50. Koenraadt CJM, Möhlmann TWR, Verhulst NO, Spitzen J, Vogels CBF. Effect of overwintering on survival and vector competence of the West Nile virus vector Culex pipiens. Parasites and Vectors [Internet]. BioMed Central; 2019; 12:1-9.

51. Robich RM, Denlinger DL. Diapause in the mosquito Culex pipiens evokes a metabolic switch from blood feeding to sugar gluttony. Proc Natl Acad Sci U S A. 2005; 102:15912-7.

52. Chevalier V, Tran A, Durand B. Predictive modeling of west nile virus transmission risk in the mediterranean basin: How far from landing? Int J Environ Res Public Health. 2013; 11:67-90.

53. Moirano G, Gasparrini A, Acquaotta F, Fratianni S, Merletti F, Maule M, et al. West Nile Virus infection in Northern Italy: Case-crossover study on the short-term effect of climatic parameters. Environ Res [Internet]. Elsevier Inc.; 2018; 167:544-9.

54. Paz S, Malkinson D, Green MS, Tsioni G, Papa A, Danis K, et al. Permissive Summer Temperatures of the 2010 European West Nile Fever Upsurge. PLoS One. 2013; 8.

55. Ewing DA, Cobbold CA, Purse B V, Nunn MA, White SM. Modelling the effect of temperature on the seasonal population dynamics of temperate mosquitoes. J Theor Biol [Internet]. Elsevier; 2016; 400:65-79.

56. Helbing CM, Moorhead DL, Mitchell L. Population dynamics of culex restuans and culex pipiens (Diptera: Culicidae) related to climatic factors in Northwest Ohio. Environ Entomol. 2015; 44:1022-8.

57. Marcantonio M, Rizzoli A, Metz M, Rosa R, Marini G, Chadwick E, et al. Identifying the environmental conditions favouring West Nile Virus outbreaks in Europe. PLoS One. 2015; 10:1-18.

58. Gates MC, Boston RC. Irrigation linked to a greater incidence of human and veterinary West Nile virus cases in the United States from 2004 to 2006. Prev Vet Med [Internet]. 2009; 89:134-7.

59. Diuk-Wasser MA, Brown HE, Andreadis TG, Fish D. Modeling the Spatial Distribution of Mosquito Vectors for West Nile Virus in Connecticut, USA. Vector-Borne Zoonotic Dis. 2006; 6:283-95.

\section{Additional Files}

Additional file 1: Figure S1. Post-hoc Tukey's comparisons between years for average mosquitoes abundance, density-dependent variable and environmental variables (coloured circles indicate a significant p-value < 0.05). Figure S2. Annual trends of the level of aridity (DMI), Normalized Difference Vegetation Index (NDVI) and temperatures (maximum, red line, and minimum, blue line, LST) from 2010 to 2018. Gray lines: monthly averages for the whole study period. Table S1. Correlation matrix of intrinsic and extrinsic variables included in the analyses (absolute correlation values higher than 0.65 are reported in boldface). Table S2. Coefficients estimates (Est.), significance and importance (Imp.) of overall period (2010-2018) and single-year models with averaged parameters 


\section{Figures}

\section{Figure 1}

Geographical location of capture sites during the years of study (2010-2018)
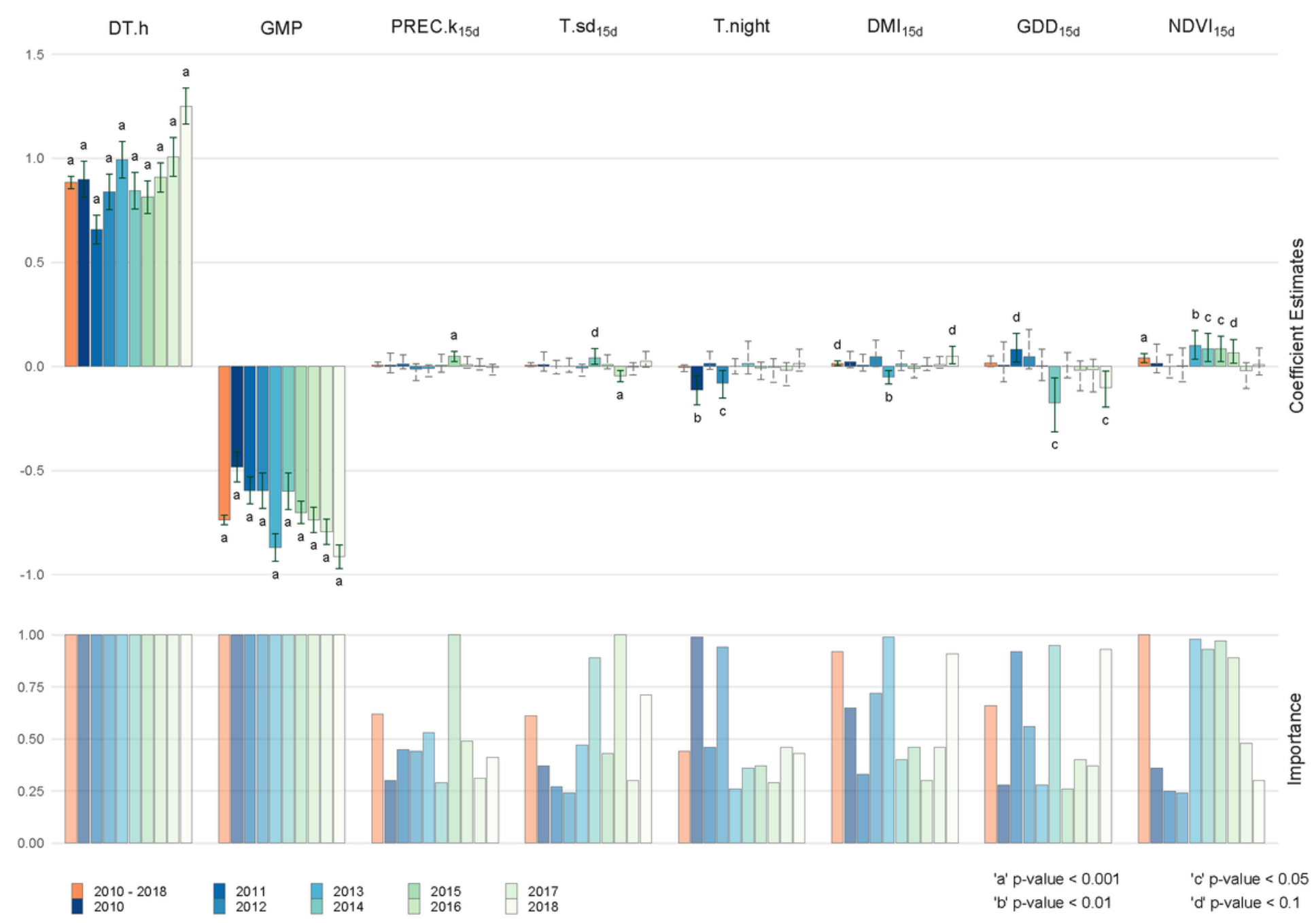

\section{Figure 2}

Graphical representation of the results of the average models per year; upper row: weighted averages of coefficients, 95\% C.I. are showed (solid lines: significant coefficients; dashed lines: non-significant coefficients); lower row: importance of the variables. Only significant variables for at least one year of study ( $p$-value $<0.1)$ are reported

\section{Supplementary Files}

This is a list of supplementary files associated with this preprint. Click to download. 
- SuppIMat20191219.pdf

Page 21/21 